\title{
EVALUATION OF INFORMATION CULTURE LEVELS FORMATION OF YOUNG TEENAGERS UNDER CONDITIONS OF A SECONDARY EDUCATIONAL INSTITUTION
}

\author{
Liubov Trifanina \\ Department of social pedagogics \\ National Pedagogical Dragomanov University \\ 9 Pirogova str., Kyiv, Ukraine, 01601 \\ LubaS92@ukr.net
}

\begin{abstract}
Today the mastering of information culture by the young generation is an important necessity, connected with information progress that takes place in the modern society. The process of information culture formation of young teenagers provides, first of all, the study and evaluation of information culture formation of pupils of this age. Thus on the base of secondary educational institutions was realized the ascertaining stage of our experimental study as to the state of information culture levels formation in young teenagers. The ascertaining experiment took place in few stages. At the first stage the content-analysis of annual plans of the upbringing work of secondary educational institutions and annual plans of the upbringing work of form-masters was realized. At the second stage the author's questionnaire was realized for young teenagers, their parents and teachers, and the results were analyzed. The involvement of parents and teachers at this stage allowed us to evaluate more objectively and precisely the parameters of information culture formation of young teenagers (knowledge about information culture bases, a desire to receive information and to master it, a striving for share information with other people and ability to interest them in information), today state of information culture in a secondary educational institution and to receive advices as to its formation among pupils of this age category. For the more essential confirmation of the veracity and exactness of the received results of optants questionnaire the methods of mathematical statistics were used (mode, median, mean value and Fisher parametric criterion). At the third stage the pedagogical evaluation of parameters of information culture formation was realized using diagnostic methods, methods of observation and expert evaluation. The fourth stage provided the results processing and the determination of information culture formation levels of young teenagers. The received results of information culture formation levels of young teenagers allowed us to confirm the necessity of technological support introduction as to the improvement of the information culture level of young teenagers under conditions of a secondary educational institution.

Keywords: young teenagers, teachers (who work with young teenagers), parents of young teenagers, secondary educational institution, information culture, parameter of information culture formation, optimal level, sufficient level, insufficient level, Fisher parametric criterion (F-criterion).
\end{abstract}

\section{Introduction}

The modern information society needs today from the future young generation the free orientation in great flows of information, abilities and skills that provide an individual information activity, directed on satisfying own needs. So, there is a necessity in information culture formation among young teenagers under conditions of a secondary educational institution. The process of information culture formation of young teenagers provides, first of all, the study and evaluation of the state of information culture formation levels of pupils of this age.

\section{Analysis of literary data and statement of the problem}

We collected diagnostic methods from the special scientific literature. Thus, from the collection of psychological tests [3] we used the specialized Munsterberg test for comprehension. From the textbook "The practical work of a school psychologist" [9] was chosen the questionnaire "The study of pupils' cognitive activity". The method "Simple analogies" was used from the textbook of age psychology [4]. From the handbook for psychologists and teachers [5] was used the method "Directionality and acquirement of knowledge". The test "Evaluation of communication level" was used from the handbook for practical psychologists [10]. 
But at the same time we elucidated that the aspect of an evaluation of the state of information culture levels formation of young teenagers under conditions of a secondary educational institution is not sufficiently elucidated in the theory and practice of the modern pedagogical science.

\section{Aim and tasks of research}

The aim of our paper is the study of the state and diagnostics of the levels of information culture formation of young teenagers under conditions of a secondary educational institution.

Tasks:

1. Content-analysis of the school documentation. teachers.

2. Processing of the results of the author's questionnaire for young teenagers, parents and

3. Pedagogical evaluation of the parameters of information culture formation using diagnostic methods, methods of observation and the expert evaluation.

4. Determination of information culture formation levels of young teenagers.

\section{Methods}

At this stage of our experimental research were used the theoretical (content-analysis of the school documentation and comparative analysis) and empirical methods (author's interrogation of young teenagers, their parents and teachers; method of expert evaluations; observation method; methods of mathematical statistics).

\section{Results of research}

The ascertaining state of our experimental research as to the state of information culture formation levels of young teenagers was realized on the base of secondary educational institutions.

This stage of the experimental research included: 358 persons - young teenagers of 5-6 classes of secondary educational institutions; 100 persons - parents (whose children study in 5-6 classes); 50 persons - teachers (form-masters, teachers of academic subjects, director assistants for upbringing work, who work with this age category of children in these educational institutions).

The ascertaining experiment took place in few stages. At the first stage the content-analysis of annual plans of the upbringing work of secondary educational institutions and annual plans of the upbringing work of form-masters was realized. At the second stage the author's questionnaire was realized for young teenagers, their parents and teachers, and the results were analyzed.

At the third stage the pedagogical evaluation of parameters of information culture formation was realized using diagnostic methods, methods of observation and expert evaluation. The fourth stage provided the results processing and the determination of information culture formation levels of young teenagers.

Thus, the first stage at the beginning of the ascertaining stage was the study of all annual plans of the upbringing work of secondary educational institutions and form-masters in general, aimed at the determination of the information culture problem in secondary educational institutions and separation of upbringing hours that would favor the information culture formation of young teenagers. Totally there were analyzed fourteen annual plans of form-masters' upbringing work and five plans of the secondary educational institutions upbringing work. We analyzed all plans in generalization, because a form-master's upbringing work plan is subordinated to the general annual plan of the school upbringing work that, in its turn, is guided by the Ministries of science and education and youth and sport of Ukraine.

The content-analysis of the school documentation gave us a possibility to make the following conclusions: the upbringing work of a secondary educational institution is realized by the following directions: upbringing of patriotism; formation of legal behavior; prophylaxis of harmful phenomena; formation of healthy life style; support of safe life activity; formation of ecological upbringing; thematic holidays; formation of esthetical education; volunteering; psychodiagnostics of pupils; work with parents. $\square$ So, we can note that in all five $(100 \%)$ annual plans of the upbringing work and fourteen (100\%) form-masters' annual plans the topic of information culture is not traced in the list of upbringing arrangements, discussions, lectures, actions, class hours and so on. Only 
in two (40 \%) annual plans of secondary educational institutions (four (28,57 \%) form-masters' annual plans) we noted that upbringing hours for the Internet safety and the pupil's correct behavior with a computer are given within the direction of healthy life style formation. But in these annual plans, of both form-masters and secondary educational institutions are not enough tasks, directed on acquiring knowledge, abilities and skills of a young teenager behavior in the information environment. This fact gives us grounds to ascertain that secondary educational institutions pay not enough attention to the formation of information culture of young teenage pupils.

Our next task at this stage of the ascertaining experiment was the questionnaire [8], aimed at the determination of the following parameters of information culture formation of young teenagers: knowledge about the bases of information culture, a desire to acquire information and to master it, a striving for share information, ability to interest other people with it. This questionnaire included not only young teenagers but also certain number of their parents and teachers, because based on their views, we tried to evaluate the aforesaid parameters of information culture formation of young teenagers, today state of information culture in a secondary educational institution more objectively and precisely and to receive advices as to its formation among pupils of this age category. The separate tests were elaborated for young teenagers, parents and teachers.

For determining the state of young teenagers' information culture in a secondary educational institution for today and receiving advices for its formation, at the beginning we tried to evaluate parents' views, analyzing the content of their answers to questions on this subject in the questionnaire for parents.

The first analyzed question was "Do you know the notion "information culture?" (information culture it is a systematized totality of knowledge, abilities and skills that allow to orient in the information environment freely), because it characterizes parents' knowledge in this subject and gives us a possibility to accent attention on their advices, offers and correspondent ideas as to this problem in further.

The analysis of this question testified that 73 (73,00\%) didn't give any answer and $27(27,00 \%)$ parents answered this question as following: 11 (11,00\%) parents - it is knowledge about the correct interaction with information, $8(8,00 \%)$ parents - it is an ability to find necessary information sources, $5(5,00 \%)$ parents - it is an ability to find information and use it effectively, and (3,00\%) parents it is a totality of knowledge, abilities and skills that provides information activity realization. So, we may made the conclusions that most parents don't understand the notion "information culture", correspondingly, most of them cannot give us useful advices and introduce their offers as to its formation and the change of the state in a secondary educational institution. And we may also assert that their children, young teenagers in our case, don't understand this notion, because the children's understanding very often depends on the parents' one.

The determinative questions in our analysis were "Does the secondary educational institution pays enough attention to information knowledge of your children? What must be done for that?" and "Are you satisfied with aspects of information culture formation of your children that are present in your secondary educational institution for today? What would you recommend to do?"

Thus, the analysis of the first question gave us grounds to make the following conclusions: $89(89,00 \%)$ parents think that a secondary educational institution pay not enough attention to information knowledge of their children, $11(11,00 \%)$ parents - didn't express their opinion on this subject at all. And only $14(14,00 \%)$ of $89(89,00 \%)$ parents - made their offers as to the increase of attention to information knowledge of their children. Among them: to give themes, directed on information knowledge acquirement in upbringing hours; to create specialized out-class activities.

The analysis of answers to the last question demonstrated that $94(94,00 \%)$ were not satisfied, because they thought that they are practically absent, and only 27 (27,00\%) parents recommended us what to do with it. Thus, $18(18,00 \%)$ parents recommended to pay attention of information culture at upbringing hours, and $9(9,00 \%)$ parents - to provide upbringing arrangements and so on. And $6(6,00 \%)$ parents missed this question at all.

No less important in our analysis was the question "Do you find it necessary to form information culture in your children?", because we can prove the necessity of information culture formation in a secondary educational institution based on these data. 
Our analysis of this question allowed us to state that $82(82,00 \%)$ parents answered "yes", despite the fact that they don't understand the definition of information culture but want their children to have these knowledge and master information culture. And only 18 (18,00\%) parents desist from an answer.

Rather topical for our analysis were the questions "Have your children to apply the culturological approach at the work with information?" and "Is it enough for today for your children to be limited only by personal computer knowledge?", because they determined the necessity of information culture in young teen age.

Having analyzed these questions, we received the results: for the first question "Have your children to apply the culturological approach at the work with information?" $85(85,00 \%)$ parents answered "yes", 11 (11,00\%) parents didn't answered it and 4 (4,00\%) parents answered "yes" with the substantiation that any interaction with information must be based on its understanding as a cultural process. To the second question "Is it enough for today for your children to be limited only by personal computed knowledge?" - 92 (92,00\%) parents answered "no" without substantiating it, and only $8(8,00 \%)$ parents substantiated their negative answer in such a way: it is necessary to develop comprehensively.

As a result of the analysis of specially elaborated test questions for parents we elucidated that information culture of young teenagers in a secondary educational institution is absent, and the content of the upbringing work of it needs the elaboration and introduction of upbringing arrangements, directed on information culture formation.

Using the other ones, we evaluated the views of teachers, who work at secondary educational institutions and teach pupils of 5-6 classes. We analyzed the questions from the questionnaire for teachers for this aim.

Thus, our first question for the analysis was "What is pupil's information culture, from your point of view?", because it characterizes teachers' erudition in this theme that, in its turn, allows us in further to consider their offered advices at to the formation of information culture of young teenagers in a secondary educational institution.

Analyzing their answers, were made the conclusions that $12(24,00 \%)$ didn't give any explanation as to this notion and the other $38(76,00 \%)$ teachers understand it as: $8(16,00 \%)$ teachers - knowledge about ways of finding and transmission of necessary information; 7 (14,00\%) teachers - an ability to work with information sources independently; 7 (14,00\%) teachers - correct interaction with information; $6(12,00 \%)$ teachers - an ability to work with information purposefully and to use it for receiving different sources; 4 (8,00\%) teachers - an ability to analyze information and use it effectively; $3(6,00 \%)$ teachers - erudition in knowledge, related to information; $3(6,00 \%)$ teachers - systematized totality of knowledge, abilities and skills that provide the optimal realization of an individual information activity. So, we may state that the most part of teachers orient in this question.

The question "From our point of view, is it urgent to form information culture in young teenage pupils for today?" is important for our analysis, because it determines the necessity of information culture formation in a secondary educational institution.

The analysis of this question allowed us to note that all $50(100,00 \%)$ teachers find it necessary to form information culture, substantiating it in such a way: $14(28,00 \%)$ teachers - Internet is today a single information source for pupils, $8(16,00 \%)$ teachers - there are a lot of accesses to information now, but pupils are not able to work with it at all, 7 (14,00\%) teachers - pupils must be able to comprehend fast and correctly and analyze large volumes of information, $4(8,00 \%)$ teachers - teachers must cope with today information sources that help in the study, $3(6,00 \%)$ teachers pupils must have knowledge and abilities for the effective information activity, $3(6,00 \%)$ teachers - pupils must be able to transform information in knowledge. The other $11(22,00 \%)$ teachers didn't give any substantiation for their answer "yes'.

The determinative ones in this questionnaire were the questions "Does an educational institution pay enough attention to acquiring information knowledge by young teen age pupils? What must be done for that?", "How do you think, which forms of information culture creation in young 
teenage pupils are expedient?" and "What methods must be used by a teacher for the formation of information culture in young teenagers?".

Thus, to the first question "Does an educational institution pay enough attention to acquiring information knowledge by young teen age pupils? What must be done for that?" $47(94,00 \%)$ teachers answered "no", 2 (4,00\%) teachers answered "yes" and only $1(2,00 \%)$ teacher answered that "pupils have different levels of information knowledge". At that teachers didn't give any recommendations as to the improvement of pupils' information knowledge under conditions of a secondary educational institution.

To the second question "How do you think, which forms of information culture creation in young teenage pupils are expedient?" $12(24,00 \%)$ teachers recommended us to form information culture in young teenage pupils using expeditions, excursions, exhibitions, films, meetings with specialists, $11(22,00 \%)$ teachers - lessons in libraries, $9(18,00 \%)$ teachers - playing, interactive, differential forms, $8(16,00 \%)$ teachers - round tables, conversations, $6(12,00 \%)$ teachers - group work forms with elements of a game and research activity, $4(8,00 \%)$ teachers - training activities in rooms of e-resources.

And to the last question "What methods must be used by a teacher for the formation of information culture in young teenagers?" $23(46,00 \%)$ teachers recommended us to use interactive learning methods at information culture formation of young teenagers, $12(24,00 \%)$ teachers information-communicative technologies, project methods, $11(22,00 \%)$ teachers - methods of analysis, generalization, comparison, $1(2,00 \%)$ teacher - method of flash-questionnaire, visual learning methods. And only $3(6,00 \%)$ could not give us recommendations in this question.

The question "How do you think, what is not enough for teachers' work in this direction (information culture formation in young teenagers)?" is rather interesting for our analysis, because the answers to it also were certain recommendations that we can use in further.

Thus, among $50(100,00 \%)$ teachers - $15(30,00 \%)$ answered nothing, $9(18,00 \%)$ think that their own knowledge and possibilities are not enough for the work in this direction, $8(16,00 \%)-$ erudition in forms and methods, $7(14,00 \%)$ - information competence, $5(10,00 \%)$ - specialized training, $4(8,00 \%)$ - motivation, $1(2,00 \%)$ - binary lessons. And $(2,00 \%)$ teacher states that in a secondary educational institution are enough means for information culture formation.

For determining information culture necessity in young teen age and comparing parents' and teachers' views there were specially analyzed the questions for teachers and parents, similar by their content, namely: "Is it enough for pupils for today to get knowledge only from the computer technique?" and "Have pupils to use the culturological approach at their work with information?".

This analysis testified that to the first question "Is it enough for pupils for today to get knowledge only from the computer technique?" 39 (78,00\%) teachers answered "no", among them only $11(22,00 \%)$ teachers grounded their answer as following: $6(12,00 \%)$ teachers - pupils must be comprehensively developed, $3(6,00 \%)$ teachers - it is necessary to be able to express own thoughts and $2(4,00 \%)$ teachers - pupils must widen their horizon. And $9(18,00 \%)$ teachers desisted from an answer at all and only $2(4,00 \%)$ teachers answered "yes", arguing that it is impossible to live without knowledge of the computer technique in the modern society.

To the second question "Have pupils to use the culturological approach at their work with information?" 48 (96,00\%) teachers answered “yes, and only $5(10,00 \%)$ teachers substantiated their answers, namely: it is necessary to know, how to use information, without breaking the principle of culture-correspondence. And 2 (4,00\%) teachers did not answered this question at all.

So, teachers' answers to the questions that determines the necessity of information culture formation in young teenagers to certain extend coincide with parents' ones, proving their veracity and objectiveness of our analysis.

Thus, our results of teachers' answers analysis confirm the aforesaid conclusions, made on the base of parents' answers analysis, that young teenagers' information culture in a secondary educational institution is absent, and the content of the upbringing work in a secondary educational institution needs the development and introduction of upbringing arrangements, directed on its formation. 
Thus, for the objective analysis of the aforesaid parameters of information culture formation in young teenagers we, first of all, analyzed parents' view on their children.

Evaluating the parameter of information culture formation in young teenagers "knowledge about information culture bases" from parents' point of view, were received results that $65(65,00 \%)$ parents referred their children to the insufficient knowledge level, and $35(35,00 \%)-$ to the sufficient one. The optimal level of information culture formation of young teenagers by this parameter is absent. So, most parents think that their children don't have enough knowledge about information culture.

The parameter of information culture formation "a desire to receive information and master it" was evaluated by parents as following: $86(86,00 \%)$ parents think that their children have the insufficient level of a desire to receive information, 12 (12,00\%) parents - the sufficient level, and $2(2,00 \%)$ parents - the optimal one. So, most parents noted the insufficient level of this parameter formation in their children that is, from their point of view, children don't manifest any desire to receive new useful information.

The analysis of parents' view on such parameter of information culture formation of young teenagers as a striving for share information with others testified that $16(16,00 \%)$ parents noted the insufficient level of this parameter formation, 59 (59,00\%) parents - the sufficient level, and $25(25,00 \%)$ parents - the optimal level. So, most parents think that their children, referred to the sufficient and optimal level, want to share information with surrounding people, but there is the certain number of parents, who noted in their children the insufficient level of this parameter formation, that is consider them as some kind of consumers, who don't want to share any information with others, but only receive it for themselves.

The analysis of parents' evaluation of such parameter of information culture formation of young teenagers as an ability to interest others in information, gave us a possibility to state that $23(23,00 \%)$ parents noted in their children the insufficient level of this parameter formation, $51(51,00 \%)$ parents - the sufficient level and $26(26,00 \%)$ parents - the optimal level. So, the essential number of parents thinks that their children need certain knowledge that would help them to interest other in information more effectively and perfectly.

As a result of parents' views as to such parameters of information culture formation as knowledge about information culture bases, a desire to receive information and to master it, a striving for share information with others and an ability to interest others in it, we made the conclusions that children of most parents need an improvement of these parameters.

In the second turn we analyzed teachers' views on their pupils.

The parameter of information culture formation of young teenagers "knowledge about information culture bases" was evaluated by teachers as following: $31(62,00 \%)$ teachers noted in their pupils the insufficient level of knowledge about information culture, 19 (38,00\%) teachers the sufficient level of knowledge about information culture and none teacher noted the optimal level of these knowledge in their pupils. So, most teachers think that their pupils are insufficiently informed in this subject and correspondingly need certain additional knowledge.

Such parameter of information culture formation as "a desire to receive information and to master it" was evaluated by teachers as following: $44(88,00 \%)$ teachers referred their pupils to the insufficient level of this parameter formation, $5(10,00 \%)$ teachers - to the sufficient one and $1(2,00 \%)$ teacher - to the optimal level. So, we may state that the essential number of teachers consider their pupils as non-interested in receiving new useful information that is absent in learning subjects.

The analysis of the teachers' evaluation of the parameter of information culture formation "a striving to share information" testified that $8(16,00 \%)$ teachers noted in their pupils the insufficient level, $28(56,00 \%)$ teachers - the sufficient level and $14(28,00 \%)$ teachers - the optimal one. So, most teachers, which pupils have sufficient and optimal levels think that their pupils want to share received information with others but there are several teachers, who noted in their pupils the insufficient level of this parameter formation that is an absence of strivings to share information with others, but the interest to its receiving from them. 
Evaluating teachers' view on such parameter of information culture formation of young teenagers as an ability to interest others in information, we noted that $11(22,00 \%)$ teachers think that their pupils has the insufficient level of this parameter formation, $26(52,00 \%)$ teachers - the sufficient level and $13(26,00 \%)$ teachers - the optimal one.

So, teachers, whose pupils belong to insufficient and sufficient levels state that their pupils must improve and enrich their skills and widen their knowledge about attracting others' attention to information.

As a result of the analysis of teachers' views on the aforesaid parameters of information culture formation of their pupils, we may made the conclusions that most teachers consider their pupils as insufficiently formed by these parameters of information culture and need their improvement, so the level of information culture must be improved too.

And at the end we realized the analysis of the aforesaid parameters of information culture formation of young teenagers directly in them.

Thus, trying to evaluate such parameter of information culture formation of young teenagers as knowledge about information culture bases we analyzed all questions and made the conclusion that to the question "How do you understand the notion "information culture?" $281(78,49 \%)$ pupils gave no answer, other 77 (21,51\%) pupils tried to outline it as following: 18 (5,03\%) pupils it is information useful and necessary for a human; 17 (4,75\%) pupils - it is an ability to present information; 15 (4,19\%) pupils - not to look, not to talk, not to write bad things; $11(3,07 \%)$ pupils - to act correctly in the Internet, social nets and in general; $9(2,51 \%)$ pupils - it is a human culture in communication; $2(0,56 \%)$ pupils - it is information about art; 2 (0,56\%) pupils - it is polite information; $1(0,28 \%)$ pupil - it is cultural news; $1(0,28 \%)$ pupil - it is a culture that doesn't violate author's rights; $1(0,28 \%)$ pupil - it is any information about how our relatives lived.

No less important for our analysis were questions: "What information sources do you know?", "What amount of information you have for today?". The analysis of answers demonstrated that $104(29,05 \%)$ pupils don't separate these questions at all, because they tried to answer them almost equally, 88 (24,58\%) pupils answered only one of them, but incorrectly, $66(18,44 \%)$ didn't answer them at all and only $100(27,93 \%)$ wrote the correct answer to one of these questions.

On Fig. 1 we determined the results of answers to these questions.

On this question we may graphically see what number of young teenage pupils in percents gave correct answers on set questions in the questionnaire as to information sources and information carriers.

So, 60 pupils that is $16,76 \%$, correctly denoted information carriers and 40 pupils that is $11,17 \%$ - information sources in the questionnaire.

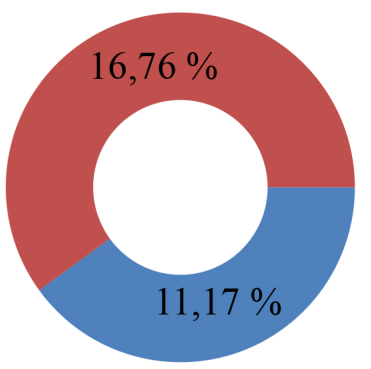

\section{Information sources \\ - Information carriers}

Fig. 1. Evaluation of young teenagers' answers to the questions: "What information sources do you know?", "What number of information carriers do you know for today?"

The analysis of the question "What the term "information" means from your point of view?" is presented on Fig. 2.

On this diagram, presented on Fig. 2 we can see that 142 (39,66 \%) pupils didn't give any answer to the set question, $151(42,18 \%)$ pupils answered incorrectly and only $65(18,16 \%)$ pupils gave the correct answer.

The question "Do you know about the holiday "World information day"? demonstrated the full absence of knowledge on this subject in 358 (100\%) pupils. 


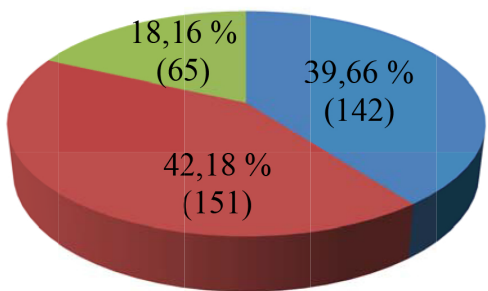

No answer

- Incorrect answer

Correct answer

Fig. 2 Evaluation of young teenagers' answers to the question "What the term "information" means from your point of view?"

According to the result of the analysis of questionnaire data as to the parameter of knowledge about information culture we may make the conclusions that despite the correct answer to certain questions, the number of points summarily didn't exceed the correspondent points of insufficient and sufficient levels. Thus in $132(36,87 \%)$ young teenagers information culture knowledge correspond to the sufficient level, in $226(63,13 \%)$ young teenagers - to the insufficient one. The optimal level by this parameter of information culture formation of young teenagers is absent.

The next analyzed parameter of information culture formation is an ability to interest others in information. This analysis gave us possibilities to note that among 358 (100\%) pupils of 5-6 classes $265(74,02 \%)$ don't pay attention to certain details, which use helps to interest others in information, because $79(22,07 \%)$ pupils - don't looks after their prosody, $66(18,44 \%)$ don't pay enough attention to the enrichment of their language, $78(21,79 \%)$ - don't use kinesics, $57(15,92 \%)$ - don't care about the own image, 98 (27,37\%) don't look after their speech expressiveness, $95(26,54 \%)$ - don't use an additional visual material.

$358(100 \%)$ young teenagers were divided by the parameter of an ability to interest other in information in correspondent levels, where: $80(22,35 \%)$ young teenagers had the insufficient level of abilities, 185 (51,68 \%) - the sufficient level, 93 (25,98\%) - the optimal one. So, most young teenagers may interest others in information but they have not enough certain knowledge, which use could correct personal abilities by their enrichment and improvement, in such a way directing the process of attracting attention to information on the effectiveness only.

On Fig. 3 is presented the analysis of such parameter of information culture formation of young teenagers as a desire to receive information.

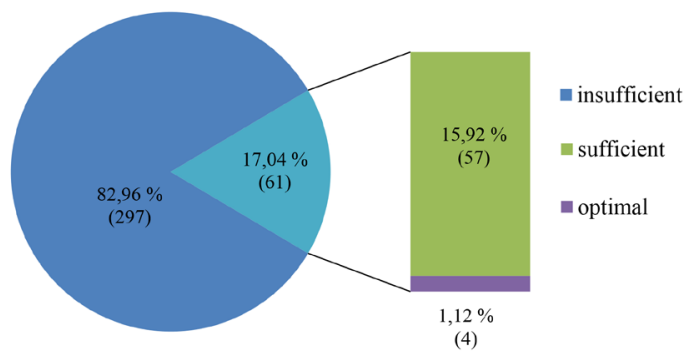

Fig. 3 Evaluation of formation of the parameter "a desire to receive information and to master it"

On the diagram, presented on figure 3 we can see that in 297 (82,96\%) young teenage pupils was observed the insufficient level of formation of the parameter "a desire to receive information" that means that they are not attracted and interested by unknown information beyond the school plan and they don't like to develop themselves. In 57 (15,92\%) young teenage pupils this parameter corresponds to the sufficient level and in $4(1,12 \%)$ - to the high one. Totally $61(17,04 \%)$ young teenage pupils expresses a desire to cognize new useful knowledge, not studied at school. Although it is not a permanent interest and longing for the own development, but their partial aspiration for paying attention to something new, unknown, equally favors their comprehensive development. So, it may be concluded that most young teenage pupils have almost no desire to receive new useful information, not related to school disciplines. The analysis of the parameter "a striving for share information with others" is presented on Fig. 4. 


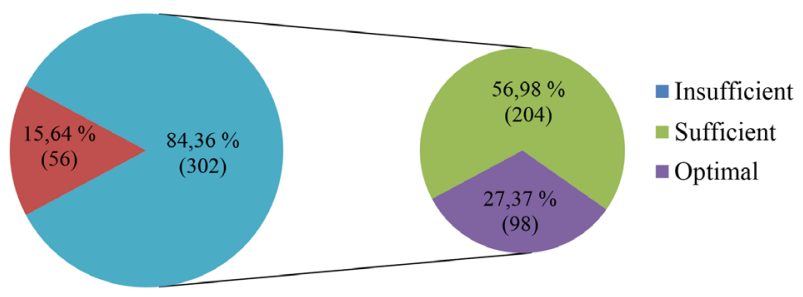

Fig. 4. Evaluation of formation of the parameter "a striving for share information with others"

On this figure we can observe that $56(15,64 \%)$ young teenage pupils has the insufficient level of this parameter formation. It means that they don't want to share information with surrounding people, cognize it for themselves only and belong to the more introvert type. In $302(84,36 \%)$ young teenage pupils this parameter is within norm, at that: 204 (56,98 \%) young teenage pupils has the sufficient level of strivings to share information with others, $98(27,37 \%)$-the optimal one. So, based on the aforesaid data, we can state that in this age most pupils want to share information, because it is their communication, at which expanse they exchange knowledge, ideas, views, especially with coevals, but there is the little number of young teenagers, who are too much concentrated on themselves for their age and treat others consumedly.

To verify the veracity of the received results of four parameters of information culture formation of young teenagers (knowledge about information culture bases, a desire to receive information and to master it, a striving for share information with others and an ability to interest other in information) from the questionnaires for parents, teachers and young teenagers and also to compare them objectively, we additionally used the method of mathematical statistics. Such methods of mathematical statistics were the calculation of the mode (Mo), median (Md), mean value $(\overline{\mathrm{X}})$ and parametric Fisher criterion (F-criterion) [6].

In Table $\mathbf{1}$ are presented the values of the mode, median and mean value according to the results of the questioning for parents, teachers and young teenagers.

In this table " $\mathrm{P}_{1}$ " is interpreted as the parameter of information culture formation of young teenagers "knowledge about information culture bases", " $\mathrm{P}_{2}$ " - a desire to receive information and to master it, " $\mathrm{P}_{3}$ " - a striving for share information with others and " $\mathrm{P}_{4}$ " - an ability to interest others in information.

\section{Table 1}

Calculations by the methods of mathematical statistics

\begin{tabular}{|c|c|c|c|c|c|c|c|c|c|c|c|c|}
\hline \multirow{3}{*}{ Parameters (IC) } & \multicolumn{12}{|c|}{ Methods of mathematical statistics } \\
\hline & \multicolumn{4}{|c|}{ Mode (Mo) } & \multicolumn{4}{|c|}{ Median (Md) } & \multicolumn{4}{|c|}{ Mean value $(\overline{\mathbf{X}})$} \\
\hline & $\mathbf{P}_{1}$ & $\mathbf{P}_{2}$ & $\mathbf{P}_{3}$ & $\mathbf{P}_{4}$ & $P_{1}$ & $\mathbf{P}_{2}$ & $\mathbf{P}_{3}$ & $\mathbf{P}_{4}$ & $\mathbf{P}_{1}$ & $\mathbf{P}_{2}$ & $\mathbf{P}_{3}$ & $\mathbf{P}_{4}$ \\
\hline Parents & 0 & 0 & 1 & 1 & 0 & 0 & 1 & 1 & 0,35 & 0,16 & 1,09 & 1,03 \\
\hline Teachers & 0 & 0 & 1 & 1 & 0 & 0 & 1 & 1 & 0,38 & 0,14 & 1,12 & 1,04 \\
\hline Young teenagers & 0 & 0 & 1 & 1 & 0 & 0 & 1 & 1 & 0,37 & 0,18 & 1,12 & 1,04 \\
\hline
\end{tabular}

Thus, on this table we can see that the values of these methods of mathematical statistics as the mode and median completely coincide in parents, teachers and young teenagers, and the mean value of their results is practically equal. It is the confirmation of the fact that the received results from the questionnaires for young teenagers don't differ from the ones, received from the questionnaires for parents and teachers. So, young teenagers gave us the true answer and correctly evaluated the level of own parameters of information culture formation, because parents' and teachers' views on these levels of parameters of information culture formation of young teenagers coincided with their views on themselves. 
For the more essential confirmation of the veracity and exactness of the received results of the questioning of our optants, the parametric Fisher criterion (F-criterion) was used.

Fisher criterion (F-criterion) was calculated for each parameter of information culture formation of young teenagers by the special formula (1). At the calculations the points of the levels of the parameters of information culture formation of young teenagers, parents and teachers, received after the author's questioning were used. At the beginning the points of young teenagers and their parents were calculated, then the ones of young teenagers and their teachers.

$$
\mathrm{F}_{\text {emp. }}=\frac{\mathrm{D}_{\mathrm{x}}}{\mathrm{D}_{\mathrm{y}}}
$$

where, $\mathrm{D}_{\mathrm{x}}$ and $\mathrm{D}_{\mathrm{y}}-$ more and less dispersion of the considered samples. It is calculated by the special formula (2) [1].

$$
\mathrm{D}=\frac{\sum_{\mathrm{i}}^{\mathrm{n}}=1(\mathrm{x}-\overline{\mathrm{x}})^{2}}{\mathrm{n}}
$$

Below in Table 2, 3 are presented the calculations of dispersion and Fisher criterion, where $\mathrm{F}_{\text {emp.1 }}$ - calculations of Fisher criterion for the parameter of information culture formation "knowledge about information culture bases", $\mathrm{F}_{\text {emp.2 }}$ - a desire to receive information and to master it, $\mathrm{F}_{\text {emp.3 }}$ - a striving for share information with others, $\mathrm{F}_{\text {emp.4 }}$ - an ability to interest others in information. In Table 2 the numeration of "P" corresponds to the aforesaid parameters of information culture formation of young teenagers by Fisher parametric criterion.

Table 2

\begin{tabular}{|c|c|c|c|c|}
\hline Optants & "P $P_{1} "$ & "P ${ }_{2} "$ & "P $P_{3} "$ & "P $\mathbf{P}_{4}$ \\
\hline Parents & 0,23 & 0,17 & 0,42 & 0,48 \\
\hline Teachers & 0,23 & 0,18 & 0,41 & 0,49 \\
\hline Young teenagers & 0,24 & 0,16 & 0,43 & 0,49 \\
\hline
\end{tabular}

Calculations of dispersion (D)

Table 3

Calculations of Fisher parametric criterion

\begin{tabular}{cccc} 
Optants & \multicolumn{3}{c}{ Fisher criterion for four parameters (IC) } \\
& $\mathbf{F}_{\text {emp.1 }}$ & $\mathbf{F}_{\text {emp.2 }}$ & $\mathbf{F}_{\text {.emp3 }}$ \\
\hline Young teenagers and parents & 1,02 & 1,03 & 1,03 \\
Young teenagers and parents & 1,03 & 1,05 & 1,04
\end{tabular}

Before calculating Fisher criterion for (F-criterion) for each parameter of information culture formation of young teenagers we made the assertion that if the received empirical value of $\mathrm{F}_{\text {emp. }}$ doesn't exceed the table one there are grounds to accept that the general dispersions of the considered samples are equal, and it means that young teenagers together with their parents and teachers gave us the equal results, so these results may be considered as true ones. And if, on the contrary, the empirical $\mathrm{F}_{\text {emp. }}$ value is more than the Table 1, the general dispersions of the considered samples are different that is the results of out optants differ, so they cannot be considered as true ones. The table value $\mathrm{F}_{\text {crit }}$, for first two samples (young teenagers and parents) and for other two samples (young teenagers and teachers) is 1,07 at the assertion of error opinion risk in five cases of hundred (significance level $=\%$ or 0,05 ), taking into account freedom degrees, equal according to the formula (3) to the optants number minus one in each sample $\left(n_{1}=100\right.$ or 50 and $\left.n_{2}=358\right)$. 


$$
\mathrm{k}_{1}=\mathrm{n}_{1}-1, \mathrm{k}_{2}=\mathrm{n}_{2}-1 \text {. }
$$

Let's compare the received $\mathrm{F}_{\text {emp. }}$ values with the table ones. The result of all table values is less than the table one, so we can make the conclusion that the general dispersions of the samples, considered above, are equal that proves the veracity of our results, received from optants.

The third stage of our ascertaining experiment was in the study of such parameters of information culture formation of young teenagers as receptibility to information, information directionality, an ability to the independent obtainment of information, a logic character of speech and communicability, for which evaluation the diagnostic methods were used.

Thus, for studying the parameter of receptibility to information, we used the specialized Munserberg test for perception, aimed at the determination of the speed and exactness of information perception by a young teenager. The analysis of this parameter is presented on figure 5 [3].

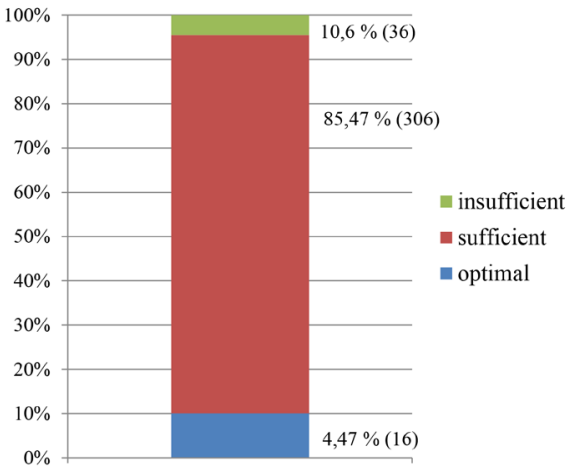

Fig. 5 Evaluation of the parameter "receptibility to information"

From this figure we can make the conclusion that $306(85,47 \%)$ young teenagers have the sufficient level of perception that is it is within norm, but there are cases, when they have not enough either time to perceive certain information or they cannot reproduce it exactly. In $16(4,47 \%)$ ones - perception is at the insufficient level. It means that young teenagers need help from adults at the determination of an essential content of information for its correct understanding and exact reproduction. And only $36(10,06 \%)$ young teenagers have the optimal perception level that conditions fast understanding and exact reproduction of any unknown information.

So, according to the above given data we can state that in most cases young teenagers cannot perceive and exactly reproduce the received information unassisted by adult competent people, because they have not enough practical abilities and skills to separate the essential main content in the received information.

The parameter "an ability to receive information independently" was studied using the questionnaire "The determination of pupils' cognitive activity" [9].

Thus, on Fig. 6 are given the data, received from the questionnaire "The determination of pupils' cognitive activity", that testify to the fact that $293(81,84 \%)$ pupils, who study in 5-6 classes don't interest in the independent cognition of new information at all, but like to make intellectual tasks in a group. The unessential number of pupils that is $59(16,48 \%)$ persons can make tasks individually, find their solutions independently and sometimes even receive new information independently, but at this type of activity they have not enough rational approach. Only 6 (1,68 \%) pupils want to receive knowledge independently, at that they are guided by the rational approach in their obtaining and occupy an active position in studying new. (Fig. 6).

So, most pupils of 5-6 classes like to obtain knowledge collectively and to work in a group, because they have not enough knowledge, abilities and skills for the independent processing of new information. They are not able to separate, to organize their independent work and to treat it rationally.

For the evaluation of the parameter "communicability" we adapted and used the test "The evaluation of communication level" [10]. On Fig. 7 are marked the levels of communicative activity of young teenagers. 


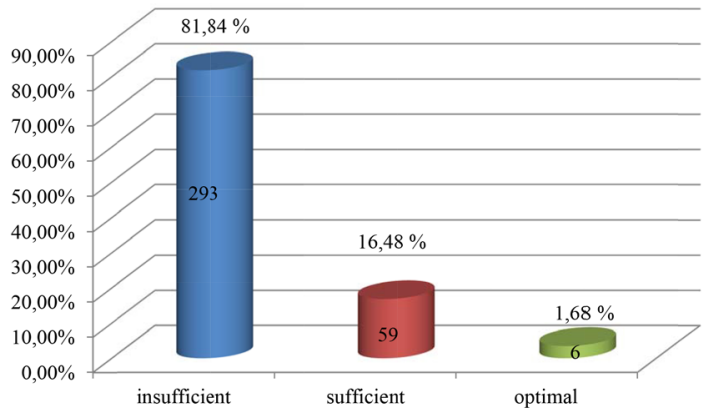

Fig. 6. Evaluation of formation of the parameter "an ability to the independent obtainment of information"

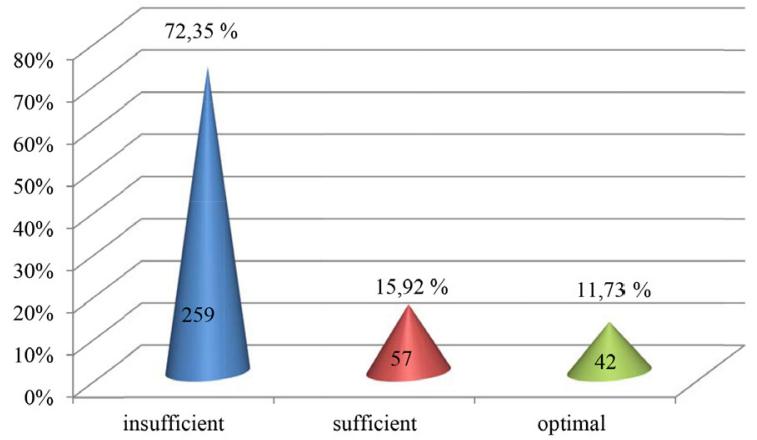

Fig. 7. Evaluation of formation of the parameter "communicability"

Thus, this histogram testifies to the fact that $52(14,53 \%)$ young teenagers demonstrate the insufficient level of a communicative activity, $230(64,25 \%)$ - the sufficient level of a communicative activity and $76(21,23 \%)$ - the optimal level of a communicative activity. It means that most young teenagers like to communicate with their coevals. Being with unknown people they find a common theme and contacts fast. Young teenagers, which communicative activity is at the optimal level, may not only take an active participation in discussions, interesting for them, but support any theme of their interlocutor with pleasure, at that expressing own ideas. Certain keenness is inherent to them in conversations. In young teenagers with the insufficient level of a communicative activity is observed a removal from active communication. They spend most time in private. And in interesting discussions they rather often like to occupy a position of "a passive observer".

So, we can state that despite their age, characterized with an active communication with coevals, there are some young teenagers that this feature is almost absent in.

Such parameter of information culture formation as information directionality was evaluated by the method "The directionality on obtainment of knowledge" [5].

As a result we revealed that $259(72,35 \%)$ young teenagers have no interest, desire and aspiration for information activity realization, $57(15,92 \%)$ - sometimes express their interest and desires to information activity and $42(11,73 \%)$ - always want to work with information. So, most young teenagers don't direct their interests on an information activity, because they have no independent ability to understand certain actions and operations that help to satisfy their information needs.

On Fig. 8 is presented the analysis of the parameter of information culture formation of young teenagers "information directionality".

For the evaluation of formation of the parameter "Logicality of speech" the method "Easy analogies" was used [4].

On figure 9 is presented the analysis of the parameter "Logicality of speech" as a diagram that allows to note that $276(77,09 \%)$ pupils of 5-6 classes demonstrate the insufficient level of this parameter that is it is rather difficult for them to express own ideas and to transmit any other information successively, with a structure, observing all logic connections. In 62 (17,32\%) pupils of 5-6 classes the parameter "logicality of speech" is within the sufficient level that is their presen- 
tation of any information is characterized with logicality, succession, structuredness, exactness and correctness of speech constructions building, but they need more time and assiduous preparation for that. An only in $20(5,59 \%)$ pupils of 5-6 classes this parameter corresponds to the optimal level. It means that their speech is characterized with reasoning, orderliness, integrity, concrete character and correct building of simple and complicated logic-grammatical constructions without applying essential efforts (Fig. 9).

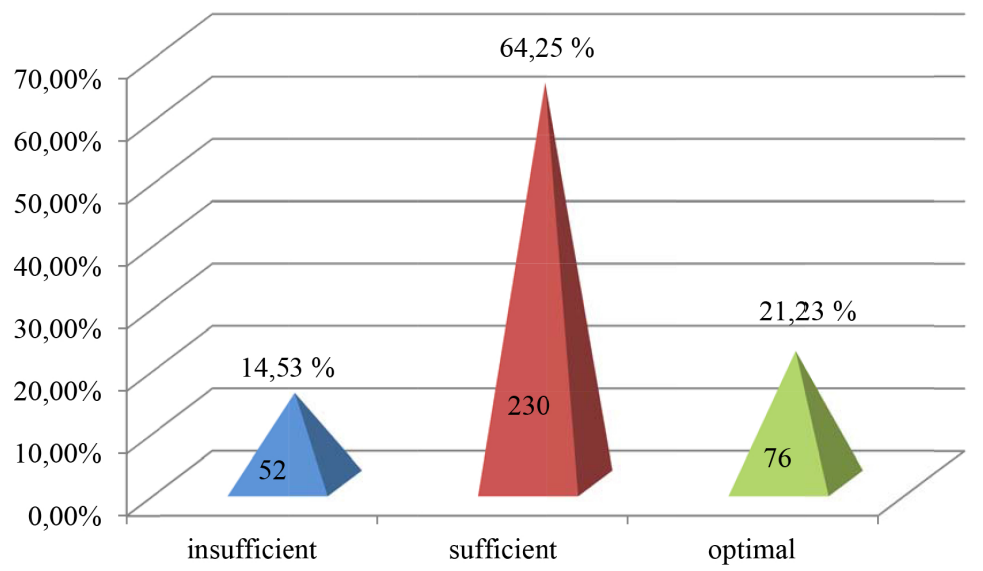

Fig. 8 Evaluation of formation of "information directionality" parameter

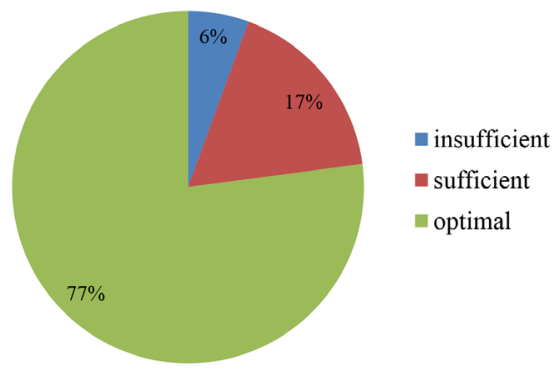

Fig. 9 Evaluation of formation of the parameter "logicality of speech"

So, the received results of such parameter of information culture formation as "logicality of speech" testify to the fact that most percent of young teenagers doesn't use logic, so their speech gains incoherence, fragmentary character, indistinctness, abstraction and incorrectness of sentences building.

For the evaluation of parameters of information culture formation of young teenagers by the behavior criterion, namely: information efficiency, information lability, information purposefulness, we used the method of expert evaluations [2] and observations [7].

For realizing these methods in each secondary educational institution we created the specialized group of experts and determined its composition. In total there were determined five specialized groups of teachers, because five secondary educational institutions were involved in the ascertaining stage of our experiment. Each group included 10 teachers (form-masters, teachers of special subjects and director's assistant in the upbringing work), summarily 50 teachers. There were competent specialists, who worked with this category of children and had certain experience of it. They tried to evaluate their pupils by such three parameters of information culture formation as information efficiency, information lability and information purposefulness, based on their behavior at school lessons. For the objective determination of these parameters formation level, we additionally used the observation method that is during the learning week the determined specialized group of experts only observed and fixed data at own activities in these classes. And only based on their previous experience of the work with these pupils and data, fixed at observations, they gave us their pedagogical evaluation as to the determined parameters of information culture 
formation by the behavior criterion at the end of the week. Having summarized all received data of each secondary educational institution, we made the general analysis for each parameter of information culture formation of young teenagers by the behavior criterion, presented on Fig. 10.

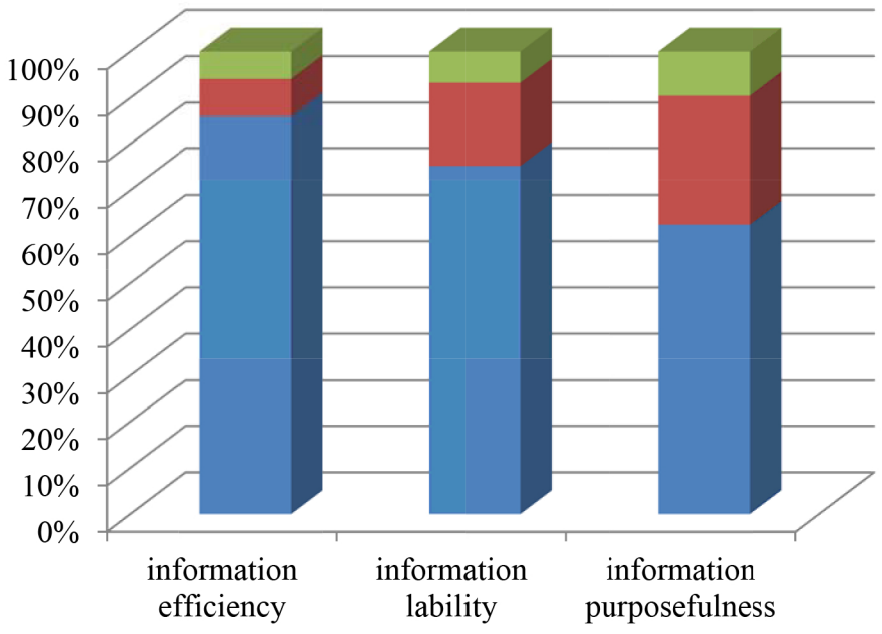

optimal

- sufficient

- insufficient

Fig. 10. Evaluation of the parameters of information culture formation by the behavior criterion

According to this histogram, let's consider the first parameter of information culture formation of young teenagers by the behavior criterion - "information efficiency". Thus, 86,03\%, that is 308 young teenagers expressed their efficiency in the work with information at the insufficient level, $8,10 \%-29$ young teenagers had the sufficient level of information efficiency and 5,87\%, that is 21 young teenager persons demonstrated the optimal level of information efficiency. So we can make the conclusions that the small number of young teenagers, which "information efficiency" parameter is at the sufficient and optimal levels can work with information fast. Their actions are characterized with correctness and exactness. But young teenagers, that the sufficient level of the parameter was revealed in, sometimes spend more time for this type of activity. And to the great regret, in most young teenagers with the insufficient level of this parameter, information activity realization is attended with slow, non-coordinated, wrong actions and operations and obligatory needs a side help and survey of a competent specialist.

The following parameter of information culture formation of young teenagers by the behavior criterion that will be considered is "information lability". In 75,14 \% - 269 young teenagers was reveled the insufficient level of "information lability" parameter, 18,16\% - 65 young teenagers have the sufficient level of this parameter and $6,70 \%-24$ young teenagers has the optimal level of "information lability parameter. So according to the presented data, we can state that young teenagers with the sufficient and optimal levels of "information lability" parameter demonstrate adaptability and mobility as to conditions that change rather often. But young teenagers with the sufficient level of this parameter sometimes need a help from persons, who are able to direct. Young teenagers with the insufficient level of "information lability" parameter formation demonstrated the low flexibility and mobility under unsteady conditions.

And the last considered parameter of information culture formation by the behavior criterion from the histogram is "information purposefulness". $62,57 \%$ that is 224 young teenagers has the insufficient level of "information purposefulness" parameter formation, 27,93 \% - 100 young teenagers with the sufficient level of "information purposefulness" parameter formation and $9,50 \%-34$ young teenage persons with the optimal level of this parameter formation. So, young teenagers with the sufficient level of "information purposefulness" parameter can stay in a monotonous activity and persistently attain their aims for a long time, if there are no side obstacles. Young teenagers with the optimal level of this parameter formation are able to attain the set aim at the expanse of their endurance and persistence. And most young teenagers, which "information purposefulness" parameter corresponds to the insufficient level differ from other ones by will 
weakness, irrepressibility, impatience to stay in the same activity and inability to apply efforts in attaining set aims.

According to the results of the analysis of the data, received by the method of expert evaluation and observation as to the parameters of information culture formation of young teenagers by the behavior criterion, namely "information efficiency", "information lability" and "information purposefulness", we can state that most young teenagers have the insufficient level of all these parameters.

It means that they have not enough practical abilities and skills that would favor their efficiency, lability and purposefulness at information activity.

All received results by twelve parameters and correspondent criteria of information culture in young teenagers were combined in general Table 4. The data are presented in this table in the absolute and percent values and distributed by the correspondent level of formation of the parameter of information culture of a young teenager, namely: insufficient, sufficient, optimal.

Table 4

Levels of parameters of information culture formation of young teenagers

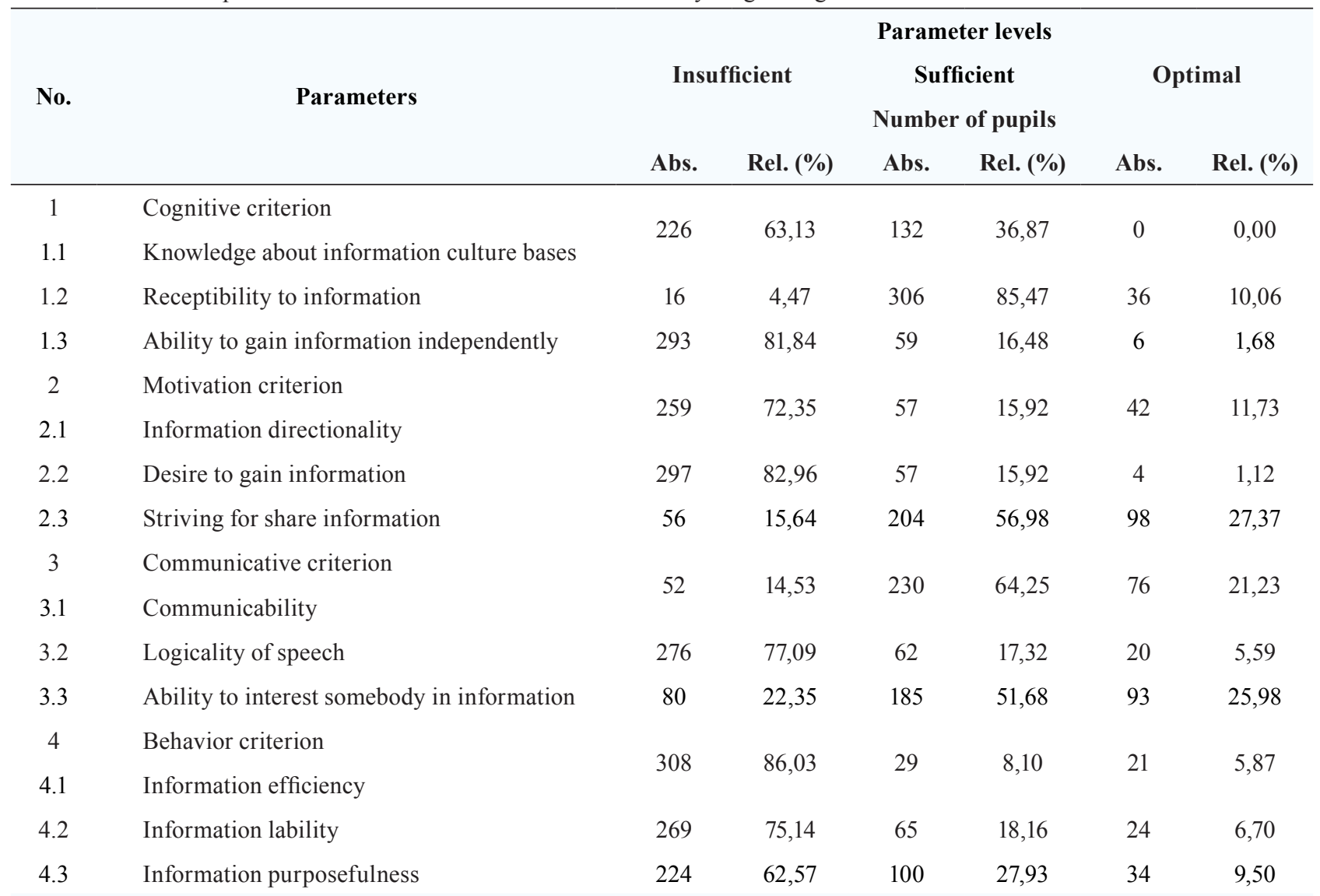

Thus, at the final stage of our ascertaining experiment we analyzed the results for all parameters and correspondent criteria of information culture of young teenagers and determined the levels of information culture formation of young teenagers, presented on Fig. 11.

The data, presented in the diagram, give us a possibility to state that among all 358 (100\%) young teenagers only in $89(24,86 \%)$ was revealed the normal level of information culture, where in $8(2,23 \%)$ young teenagers - the optimal level, in $81(22,63 \%)$ - the sufficient level. In all others, that is $-269(75,14 \%)$ young teenagers the insufficient level of information culture was observed.

So, on the base of the received results of the ascertaining stage of the experiment, we can make the conclusions that secondary educational institutions pay not enough attention to information culture of young teenagers. 


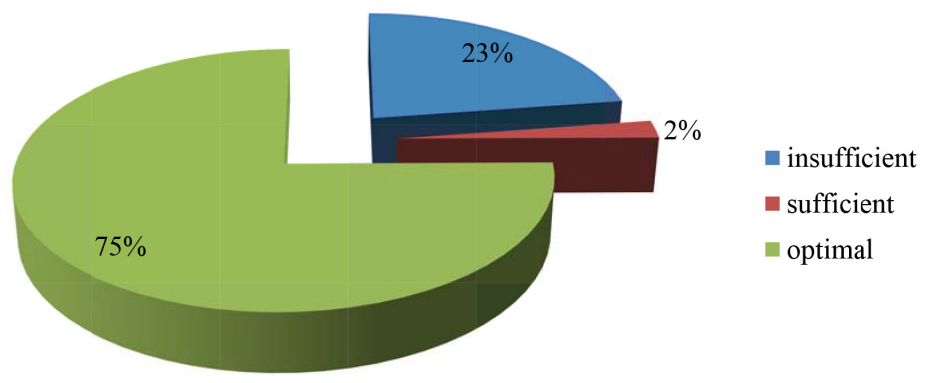

Fig. 11. Levels of information culture formation of young teenagers

\section{Discussion of results}

That is why the received results of the levels of information culture formation of young teenagers allowed us to prove the necessity to introduce the technological support as to the improvement of information culture formation level of young teenagers under conditions of a secondary educational institution.

\section{Conclusions}

As a result of the evaluation of the state of information culture formation levels of young teenagers under conditions of a secondary educational institution we made the following conclusions, so it is necessary:

1. To raise the level of information culture in young teenagers under conditions of a secondary educational institution.

2. To introduce in the upbringing work of secondary educational institutions upbringing arrangements, directed on the stimulation of information culture formation of young teenagers.

3. To activate the upbringing work of a secondary educational institution in the following directions: the acquirement of knowledge about information culture and abilities to interest other people in information; the development of logic speech, a desire to receive information and to master it and strivings to share information with others; improvement of communicability; development of an ability of independent acquirement of information; teaching of practical abilities and skills of efficiency, lability, purposefulness in the information activity; improvement of receptibility to information.

4. To introduce work forms, directed on acquirement of knowledge, abilities and skills of a young teenager's behavior in the information environment into secondary educational institutions.

\section{References}

[1] Afanasev, V. V., Sivov, M. A. (2010). Matematycheskaia statistika v pedahohike. Yaroslavl: YaHPU, 76.

[2] Hrabovetskyi, B. Ye. (2010). Metody ekspertnykh otsinok: teoriia, metodolohiia, napriamky vykorystannia. Vinitcya: VNTU 1, 170.

[3] Kasianov, S. (2006). Psikholohicheskie testy. Moscow: Eksmo, 608.

[4] Kulahina, I. Yu., Kaliutskiy, V. N. (2001). Vozrastnaia psikholohiia. Moscow: TC «Sfera», 436.

[5] Nikishina, V. B. (2003). Prakticheskaia psikholohiia v rabote s detmi s zaderzhkoy psikholohicheskoho razvytiia. Moscow. VLADOS, 128.

[6] Novikov, D. A. (2004). Statisticheskie metody v pedahohicheskikh issledovaniaykh (tipovye sluchai). Moscow: MZ-Press, 67.

[7] Orban-Lembryk, L. E. (2005). Sotsialna psykholohiia. Kyiv: Akademvydav, 448.

[8] Ortynskyi, V. L. (2009). Pedahohika vyshchoi shkoly. Kyiv: Tsentr uchbovoi literatury, 472.

[9] Pashnev, B. K. (2010). Psikhodiahnostika: praktikum shkolnoho psikholoha. Rostov-na-Donu: Fenyks, 317.

[10] Rohov, E. I. (1999). Nastolnaia kniha prakticheskoho psikholoha: Robota psikholoha so vzroslymi detmi. Korektsionnye priyomi i uprazhneniia. Moscow: VLADOS, 480. 